\title{
FEASIBILITY OF USING WAX BLOCKS TO MEASURE RAT AND POSSUM ABUNDANCE IN NATIVE FOREST
}

\author{
M.D. THOMAS ${ }^{1 *}$, J.A.BROWN ${ }^{2}$ and R.J. HENDERSON ${ }^{1 *}$ \\ ${ }^{1}$ Landcare Research, P.O. Box 69, Lincoln \\ ${ }^{2}$ Biomathematics Research Centre, Canterbury University, \\ Private Bag 4800, Christchurch \\ *Pest Solutions, P.O. Box 31-191, Christchurch
}

\begin{abstract}
Rats and possums are the predominant pest species in New Zealand forests and forest managers need to know when to control them and the success of control. This requires an accurate and practical census method. Existing census methods using footprint tracking tunnels and traps are time-consuming, which lowers the precision of the measures of pest abundance. We examined the feasibility of using a new census method based on the frequency of rat and possum bite marks in wax blocks. Results showed that rat and possum bite marks could be individually identified and appeared to give realistic estimates of pest abundance when compared to existing census methods.
\end{abstract}

Keywords: population monitoring, pest control, rats, possums.

\section{INTRODUCTION}

The ship rat (Rattus rattus) contributes directly to the demise of the North Island kokako, Callaeas cinerea, ( J.R. Hay pers. comm.), and other declining endemic bird species, by killing eggs and chicks (Moors 1983). Rats feed predominantly on invertebrates, fruits and seeds (Best 1969), and compete for these foods with a wide range of bird species. Consequently rat control, predominantly by poisoning, is frequently undertaken in forest where birds are endangered. These control operations are monitored to determine whether they have been successful in reducing rat numbers. Monitoring is also required to estimate rat numbers so forest managers can determine when they are at levels that may threaten native species.

Snap-back trapping and footprint tracking (Innes et al. 1995; Moors 1978) are used to measure rat population densities and Brown et al. (1996) showed that these methods give accurate estimates. However both have two key disadvantages. Firstly, traps and tracking tunnels are heavy so the method is labour intensive and sample sizes are restricted by the amount of equipment that can be carried. Secondly, rats are removed when using snap-back trapping which requires trap-lines to be sited at different locations for pre- and post-poison density estimates to ensure that the kill estimate reflects only the kill due to the control operation. Both factors lead to increased sampling costs and reduced precision.

A possible alternative for monitoring is the bait interference method (Bamford 1970) where the frequency of non-toxic baits eaten is recorded. Initially this method was developed to monitor possum (Trichosurus vulpecula) populations but it was found to have two major limitations. Firstly, the flour paste baits used were very palatable so possums actively searched for them and ate several baits at once. This resulted in an over estimation of possum numbers (E. Spurr pers. comm.). Secondly, the baits were eaten by other species, such as rats and ground-birds, and these could not be differentiated from the baits eaten by possums.

A promising alternative is the use of wax block baits. Wax has a low palatability and individual species can be differentiated from bite mark impressions left in the wax. This paper examines the feasibility of using wax blocks as an alternative for monitoring rats and possums in native forest. 


\section{MATERIALS AND METHODS}

Wax blocks measuring approximately 25 x 15 x $5 \mathrm{~mm}$ were moulded in plastic ice cube trays using microcrystalline wax containing $5 \%$ orange oil as an attractant. An ice-block stick was inserted into each block so the blocks could be anchored to the ground. Once the wax had hardened the blocks were removed from the trays and dipped in red coloured wax to improve visibility in the field. Skulls were collected from possums, rats, mice, hedgehogs and rabbits and were used to make simulated bite marks in wax blocks. These were compared with real bite marks collected in the field to determine whether individual species could be identified. In addition, captive possums, rats and mice were given wax blocks and their bite marks were used to identify bite marks collected in the field.

At two study sites in Northland (Trounson Kauri Reserve and Katui Reserve) rat bite mark frequencies in wax blocks were compared with capture frequencies using snap-back traps. At Trounson Kauri Reserve rats and possums were poisoned regularly during the period the wax blocks were used with cereal baits containing $0.002 \%$ brodifacoum (Talon). No poisoning was undertaken at Katui. At both study sites 100 Victor "Esy set" snap-back rat traps were set for 3 nights at 20-m intervals on five trap lines in October 1996, January 1997 and March 1997. Traps were checked daily and those that were sprung or caught rats were reset. On the first two nights of trapping 200 wax blocks were located at $10 \mathrm{~m}$ intervals on five separate lines, i.e. 40 blocks per line. The blocks were left for 2 nights and checked daily and bite marks were identified and recorded. Blocks bitten on the first night were replaced or marked to prevent double recording.

The frequencies of footprint tracking were compared with bite mark frequencies in wax blocks at Waipapa in the Central North Island. The tracking tunnels were located on a grid spaced at approximately $200 \times 50 \mathrm{~m}$ and baited at each tracking period with peanut butter. A total of 200 wax blocks were located at $10 \mathrm{~m}$ intervals on 5 individual lines i.e. 40 blocks per line alongside the tracking tunnel lines. Rats and possums were poisoned using bait stations spaced on a $150 \mathrm{~m}$ grid (Thomas 1994) firstly using cereal baits containing $0.15 \% 1080$ then with cereal baits containing $0.002 \%$ brodifacoum (Talon). A total of 8 population estimates were recorded (October 1995 to November 1997) from the footprint tracking tunnels and five estimates from the wax blocks (October 1995 to June 1997). The trend in possum bite mark at Waipapa was also compared with the trend in possum captures in 100 'Victor' leg-hold traps set for 3 nights. Capture frequencies were recorded six times between October 1995 to September 1997.

\section{Identification of bite marks}

\section{RESULTS}

The bite marks made by the captive animals and the simulated marks made by the skulls showed rats, possums, rabbits and hedgehog marks could be easily identified. However the bite marks made by captive mice were too indistinct to be accurately identified. Bite marks collected from the field were identified as having been made by rats, possums, hedgehogs, and rabbits but none were identified as having been made by mice.

\section{Rat bite marks and snap-back trap capture frequencies}

Snap-back capture rates at Trounson were almost zero which initially suggested that most of the rats had been removed or that the remaining rats were unlikely to be caught in traps. The presence of rat bite marks and the high proportion of sprung traps, showed that there were more rats present than the trapping indicated (Fig. 1).

At Katui, where no poisoning was undertaken, catch and sprung trap rates were higher than those recorded at Trounson (Fig. 2) but still less overall than the frequency of bite marks on the wax blocks.

\section{Rat bite marks and tracking tunnel frequencies}

Rat footprint tracking frequencies at Waipapa decreased markedly after 1080 poisoning (Fig. 3). Thereafter, during Talon poisoning, the frequencies remained low but appeared to undergo seasonal fluctuations with peaks in the winter (Fig. 3). Bite 


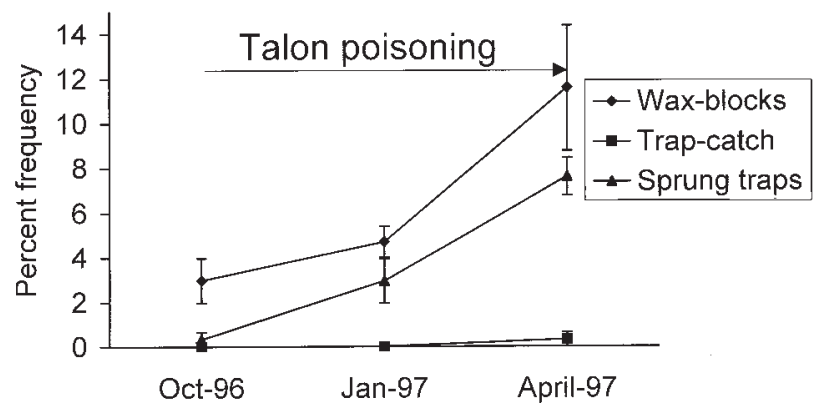

FIGURE 1: Percentage of "Victor Easy Set" snap-back traps sprung and percentage with captured rats compared with the percentage of wax blocks marked with rat bites at Trounson Kauri Reserve. Error bars are \pm S.E.

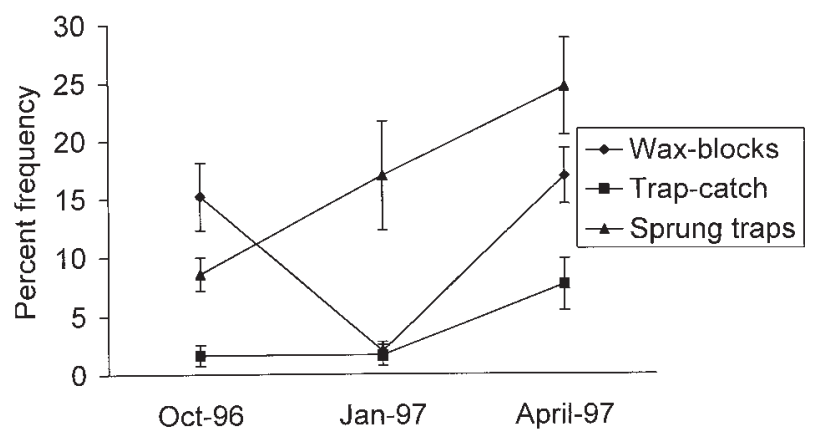

FIGURE 2: Percentage of "Victor Easy Set" snap-back traps sprung and percentage with captured rats compared with the percentage of wax blocks marked with rat bites at Katui Reserve. No poisoning was undertaken. Error bars are \pm S.E.

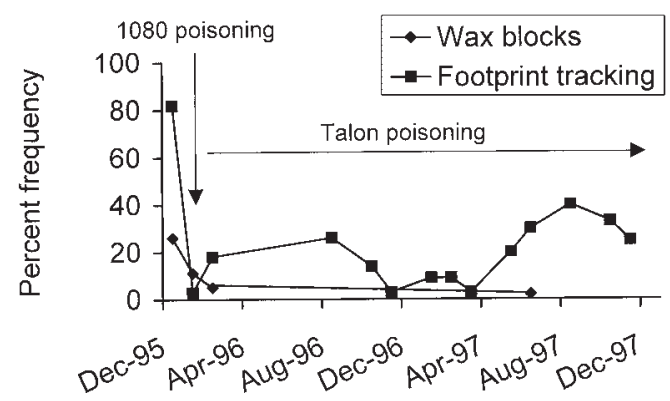

FIGURE 3: Percentage of tracking tunnels with rat footprint marks compared with the percentage of wax blocks bitten by rats at Waipapa Forest. 
mark frequencies also showed a rapid decline after the 1080 poisoning but remained lower than, and less variable than the tracking frequencies during subsequent Talon poisoning.

\section{Possum bite marks and leg-hold trap capture frequencies}

Frequencies of possum leg-hold trap captures and bite marks at Waipapa were similar during and after the 1080 poisoning (Fig. 4).

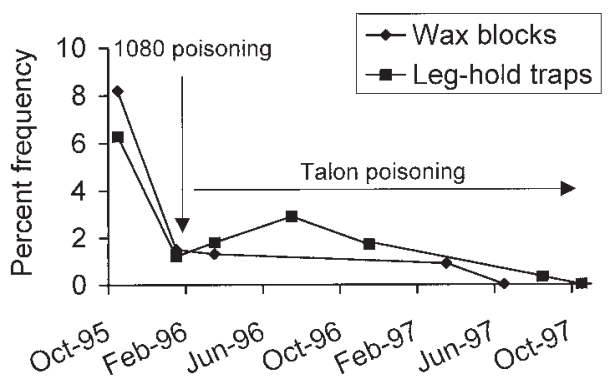

\section{FIGURE 4: Percentage of leg-hold traps capturing possums and wax blocks with possum bite marks at Waipapa Forest.}

\section{DISCUSSION}

The frequency of bite marks in wax blocks was a feasible method for measuring changes in rat and possum abundance in these study sites. Rat and possum bite marks could be individually identified, frequencies of rat bite marks exceeded trap capture frequencies (Figs. 1 and 2), and frequencies of possum bite marks aligned closely with those of leg-hold captures (Fig. 4). In particular the two agreed closely when possums were reduced during the 1080 poisoning. There was also good agreement between bite mark frequencies and footprint tracking frequencies for rats during 1080 poisoning (Fig. 3). The study also showed that it was possible to monitor both rats and possums simultaneously in areas where both species were pests. This would substantially reduce monitoring costs in areas where both pest species were present.

The wax block method was easier to employ than both the kill/leg-hold trapping and tracking tunnel methods. The blocks were light and compact, allowing hundreds to be carried at a time so monitoring could be undertaken over larger areas. Also larger sample sizes could be taken. Both these advantages would improve the precision of population estimates. In contrast, kill and leg-hold traps are heavy and bulky and capture frequencies are more likely to be influenced by operator skill. The use of tracking-tunnels was more time-consuming than using wax blocks and required the use of chemicals that were unpleasant to handle. The next question is whether the use of wax blocks gives reliable estimates of rat and possum abundance. Trials to determine this could be undertaken by simulating a rat or possum control operation and measuring actual percent kills. Kills could be measured by fitting mortality-sensing radio transmitters to the rats and possums. Alternatively, the "Zippin Removal method" could be used, where abundance is estimated using the number of animals that are progressively removed from a population using trapping, as used by Brown et al. (1996).

\section{ACKNOWLEDGEMENTS}

We would like to thank the Department of Conservation and Landcare Research for funding this study. Also we would like to thank Department of Conservation field staff in Northland and Pureora who undertook the field trials. Elaine Murphy of the Department of Conservation also gave helpful assistance and Dr Eric Spurr and Bruce Warburton of Landcare Research made helpful comments on an earlier report. 


\section{REFERENCES}

Bamford, J.M., 1970. Evaluating opossum operations by interference with non-toxic baits. Proc. N.Z. Ecol. Soc. 17: 118 - 215.

Best, L.W., 1969. Food of the roof-rat, (Rattus rattus), in two forest areas of New Zealand. N.Z.J. Sci. 12: 258-267.

Brown, K.P., Moller, H., Innes, J. and Alterio, N., 1996. Calibration of tunnel tracking rates to estimate relative abundance of ship rats (Rattus rattus) and mice (Mus musculus) in a New Zealand Forest. N.Z. J. Ecol. 20: 271 - 276.

Innes, J., Warburton, B., William, D., Speed, H., and Bradfield, P., 1995. Large-scale poisoning of ship rats (Rattus rattus) in indigenous forest of the North Island, New Zealand. N.Z. J. Ecol. 19: 5 - 17.

Moors, P.J., 1978. Methods for studying predators and their effects on native birds. pp. 47-57. In: The Ecology and Control of Rodents in New Zealand Nature Reserves, P.R. Dingwall, I.A.E. Atkinson and C. Hay, (Eds), , N.Z. Dept. Lands and Survey Information Series 4, Dept. of Lands and Survey, Wellington, New Zealand. $237 \mathrm{pp}$.

Moors, P.J., 1983. Predation by mustelids and rodents on the eggs and chicks of native and introduced birds in Kowhai Bush, New Zealand. Ibis 125: 137 - 154.

Thomas, M.D., 1994. Possum control in native forest using sodium monofluoroacetate (1080) in bait stations. Proc. 47th N.Z. Plant Prot. Conf:: 256 - 259. 